ORIGINAL ARTICLE

\title{
Association between Serum MicroRNA-21 Gene Expression, Carcinoemberyonic Antigen and Clinicopathological Character for Colorectal Cancer Amal Fathi Gharib ${ }^{1,2}$, Randa H Mohamed ${ }^{1}$, Ahmed R Abdel-Fatah ${ }^{3}$, Sara F Saadawy ${ }^{{ }^{*}}$ \\ ${ }^{1}$ Medical Biochemistry Department, Faculty of Medicine, Zagazig University, Zagazig, Egypt \\ ${ }^{2}$ Clinical Laboratory Department, Faculty of Applied Medical Science, Taif University, Saudi Arabia \\ ${ }^{3}$ General Surgery Department, Faculty of Medicine, Zagazig University, Zagazig, Egypt
}

*Corresponding author :

Sara F Saadawy

Medical Biochemistry

Department, Faculty of

Medicine, Zagazig

University, Zagazig, Egypt

E.mail:

sara_saadawy@hotmail.com

Submit Date

2019-07-08

Revise Date

2019-07-22

Accept Date

2019-07-22

\section{ABSTRACT}

Background: microRNAs (miRNAs) are tiny, noncoding RNAs that regulate gene expression on the posttranscriptional level and this may lead to cancer development. This study aimed to detect the serum levels of microRNA-21 gene expression and to assess their relation to colorectal cancer (CRC) outcome and correlate it with carcinoemberyonic antigen level. Methods: the collected blood samples from 48 subjects already diagnosed as CRC and 48 healthy controls. A quantitative reverse transcription polymerase chain reaction (qRT-PCR) was using in the measurement of the expression levels of miR-21.The obtained data were used to measure the association between serum microRNA-21 levels and clinic pathological and prognostic factors. Results: High serum expression of microRNA-21 have been correlated with greater local recurrence, TNM staging, PT staging, venous invasion, liver metastasis and recurrane $(\mathrm{p}=0.004)$, positively correlated with CEA. Conclusions: There was a correlation between the expression level of serum miR-21 and CEA, recurrence and some pathological parameters of patients with CRC. Our results suggest that circulating serum microRNA-21 is a promising tumour marker, can be used in diagnosis and prognosis of CRC.

Key words: MicroRNA-21; CEA; Colorectal cancer; Correlation

\section{INTRODUCTION}

Cosma olorectal cancer $(\mathrm{CRC})$ is still considered a major public health issue. The CRC is the fourth most common cancer in 2008 and the world's fifth biggest cause of cancer-related deaths [1].

MiRNAs are tiny (18-22 nucleotides), noncoding RNAs that have a great role in regulation of gene expression on the posttranscriptional level. These molecules play a crucial physiological and pathological role including apoptosis (programmed cell death), the ability of the cell to proliferate and differentiate. This finding indicates that MiRNAs may be double edged weapon as they act as antioncogene or oncogenes in tumorigenesis [2].

Progress in diagnosis and therapy has had a beneficial impact on enhancing general survival, with more patients diagnosed early in the disease, but the survival of patients with late stages of cancer will not be affected by this progress [3]. Long-term survival and improved patient prognosis rely at the moment of identification on the tumor stage. For screening, fecal occult blood testing and tumor markers (e.g. carcinoembryonic antigen) are commonly used with colonoscopy reserved for patients with positive fecal occult blood and CEA. CEA has been the most ordinary used biomarker in the diagnosis and follow-up of colorectal cancer due to its high accuracy and low cost. Some studies have revealed that low CEA levels were correlated with longer progression-free survival (PFS) and overall survival (OS) positively [4]. However, owing to low sensitivity and specificity, the use of CEA is limited [5]. There are presently no tests or biomarkers that 
accurately predict early tumor existence, recurrence, response to chemotherapeutic agents, and survival for long-term. Improvements are clearly needed in the early identification of CRC.

It has been found that many miRNAs that intercede cell proliferation and tumor development are upregulated in CRC, including miR-20, miR-21, miR-15b, miR-181b, and miR-200c [6, 7]. This change in different miRNAs levels has been related to diagnosis and prognosis of CRC suggesting that in clinical implementation they may be feasible biomarkers $[8,9]$. It has been found that miR21 plays a major part in cancer biology, so it could be used in detection of CRC and predicting the CRC outcome. In this study we aimed clarify role of miR-21 in CRC and its correlation with CEA level.

\section{METHODS}

\section{Study subjects}

The study was conducted in Medical Biochemistry Department and the Scientific Medical Research Center (ZSMRC) \& Department of General Surgery - Approval for the study was obtained from International Review Board (IRB), Faculty of MedicineZagazig University. This is case control study 48 adult subjects were included in it. Informed written consents were obtained from all of them to use their samples and clinical data in this study according to the Declaration of Helsinki using a dedicated form. Subjects with histopathological confirmation of the diagnosis of CRC ,Adequate hepatic, renal, cardiac and respiratory functions, Approval for enrollment in study were included in the study and exclude persons with a personal history of other malignancy, Inflammatory bowel disease, familial adenomatous polyposis were excluded, patients (or their guardians) refusing to participate in study.

Study design Subjects were classified into 2 groups: Control group: healthy volunteers, this group included 48 subjects \& diseased group: This group included 48 patients were diagnosed as CRC.
On the sampling day, demographic and clinical information was collected from all subjects: stage of cancer and tumor grade. The staging of tumors according to the American Joint Committee on Cancer TNM staging system [10, 11], history of pervious treatment, complete physical \& clinical examination was done.

Whole blood samples were collected from each participant into 5-ml RNase-free tubes. The serum was then separated, the miRNAs is extracted by the miRNeasy serum/plasma (Cat number: Q217004; Qiagen, Germany) and detection of serum CEA level were determined by means of an enzyme immunoassay test kit (Catalogue No 201-12-1715).

\section{Real-time RT-PCR}

Serum levels of miRNA biomarkers and RNU 6 were examined by real-time RT-PCR using TaqMan MicroRNA Assays (Applied Biosystems, catalog number 4427975). total RNA was reverse transcribed using TaqMan MicroRNA Reverse Transcription Kits (Applied Biosystems, catalog number 4366596) with the following conditions: $16^{\circ} \mathrm{C}$ for 30 minutes, $42^{\circ} \mathrm{C}$ for 30 minutes, $85^{\circ} \mathrm{C}$ for 5 minutes and maintained at $4^{\circ} \mathrm{C}$. Real-time PCR was conducted using MicroRNA Assay Kits and TaqMan Universal Master Mix II, no UNG (Applied Biosystems, catalog number 4440040), with the following cycling conditions: $95^{\circ} \mathrm{C}$ for 10 minutes, followed by 40 cycles of $95^{\circ} \mathrm{C}$ for 15 seconds and $60^{\circ} \mathrm{C}$ for 1 minute. Cycle threshold $(\mathrm{Ct})$ values were calculated using Step One Software v2.3 (Applied Biosystems). Expression level of miRNA-21 was normalized to those of RNU6 and determined by the $2^{-\Delta \Delta \mathrm{CT}}$ method [12].

\section{Statistical analysis}

Data were checked, entered and analysed using SPSS version 22 ,data were expressed as mean \pm SD for quantitative parametric variable , median for non parametric one ,categorical variable expressed as frequency and percentage, student $\mathrm{t}$ test, Mann Whitny, chi-squared test were used when appropriate $\mathrm{p}<0.05$ was considered statistically signifcant 
Analysis was based on the accuracy of the identified miRNAs to diagnose the presence of $\mathrm{CRC}$ as determined using Receiver Operator Characteristic (ROC) curves as Area Under the Curve (AUC) value and sensitivity and specificity

\section{RESULTS}

Serum miR-21 expression among cases and controls

The studied group show serum miR-21 expression was significantly higher among cases compared to controls $(\mathrm{p}<0.001)$ median 34.2 compared to 1.25 in cases and controls respectively (Table 1)

MiR-21 as a non-invasive biomarker for CRC diagnosis

ROC curve analysis revealed sensitivity $95.8 \%$ and specificity $91.7 \%$ (an area under the ROC curve, AUC: 0.94) which indicate that the serum miR-21 expression level could be used for the diagnosis of CRC patients with (Figure $1)$.

Relation of clinicopathological factors and high serum level of miR-21

high level miR-21 was significantly associated with TNM stage, PT classification, venous invasion, liver metastasis and recurrence $(p<0.05)$ while there were no significant association between high level and other parameters (Table 2).

CEA level among cases and controls

CEA level among cases and controls showed that the median level of CEA was significant higher among CRC patients $(\mathrm{p}<0.001)$ (Table $3)$.

CEA as a biomarker for CRC diagnosis

ROC curve analysis showed the CEA level with a sensitivity $83.3 \%$ and specificity of $95.8 \%$ (an area under the ROC curve, AUC: 0.924) so used in CRC patients as a hopeful marker in the diagnosis (Figure 2).

\section{Relation between clinicopathological} parameters and High CEA

There was no significant association between high level of CEA and clinicopathological parameter (Table 4).

\section{Correlation between miR-21 and CEA}

The study showed a highly significant correlation between CEA level and miR-21 (Figuer 3).

Table1. Serum miR-21 expression among cases and controls.

\begin{tabular}{|c|c|c|c|c|}
\hline & $\begin{array}{l}\text { Cases } \\
(n=48)\end{array}$ & $\begin{array}{l}\text { Controls } \\
(n=48)\end{array}$ & $\begin{array}{l}\text { Mann- } \\
\text { whitney }\end{array}$ & $\mathbf{P}$ \\
\hline \multicolumn{5}{|l|}{ miR-21 } \\
\hline Mean \pm SD & $3.46 \pm 1.32$ & $1.23 \pm 0.38$ & & \\
\hline Range & $1.37-5.97$ & $0.73-1.89$ & 34.2 & $<0.001 * *$ \\
\hline Median & 3.24 & 1.25 & & \\
\hline
\end{tabular}


Table 2. Relationship between clinicopathological factors and high level of serum miR-21.

\begin{tabular}{|c|c|c|c|c|}
\hline & $\begin{array}{l}\text { Total } \\
(n=48)\end{array}$ & \multicolumn{2}{|c|}{$\begin{array}{l}\text { High } \\
\text { No }\end{array}$} & $\mathbf{P}$ \\
\hline \multicolumn{4}{|l|}{ TNM } & \multirow{3}{*}{$0.004 *$} \\
\hline I-II & 30 & 6 & 20.0 & \\
\hline III-IV & 18 & 16 & 88.9 & \\
\hline \multicolumn{4}{|l|}{ Location } & \multirow{3}{*}{0.94} \\
\hline Colon & 28 & 14 & 50.0 & \\
\hline Rectum & 20 & 8 & 40.0 & \\
\hline \multicolumn{4}{|l|}{ PT } & \multirow{3}{*}{ 0.013* } \\
\hline Pt 2-3 & 32 & 8 & 25.0 & \\
\hline PT4 & 16 & 14 & 87.5 & \\
\hline \multicolumn{4}{|l|}{ Histology } & \multirow[t]{3}{*}{0.81} \\
\hline Differentiated & 36 & 18 & 50.0 & \\
\hline Undifferentiated & 12 & 4 & 33.3 & \\
\hline \multicolumn{4}{|l|}{ Size } & \multirow{3}{*}{0.1} \\
\hline$\square 5$ & 26 & 8 & 30.8 & \\
\hline$>5$ & 22 & 14 & 63.6 & \\
\hline \multicolumn{4}{|l|}{ Venous } & \multirow{3}{*}{$0.02 *$} \\
\hline No & 38 & 12 & 31.6 & \\
\hline Yes & 10 & 10 & 100.0 & \\
\hline \multicolumn{4}{|l|}{ L.N } & \multirow{3}{*}{0.39} \\
\hline No & 22 & 8 & 36.4 & \\
\hline Yes & 26 & 14 & 53.8 & \\
\hline \multicolumn{4}{|l|}{ Peritoneal Mets } & \multirow{3}{*}{0.46} \\
\hline No & 40 & 16 & 40.0 & \\
\hline Yes & 8 & 6 & 75.0 & \\
\hline \multicolumn{4}{|l|}{ Liver } & \multirow{3}{*}{$0.004^{*}$} \\
\hline No & 30 & 6 & 20.0 & \\
\hline Yes & 18 & 16 & 88.9 & \\
\hline \multicolumn{4}{|l|}{ Chemotherapy } & \multirow{3}{*}{0.09} \\
\hline No & 22 & 6 & 27.3 & \\
\hline Yes & 26 & 16 & 61.5 & \\
\hline \multicolumn{4}{|l|}{ Recurrence } & \multirow{3}{*}{$0.004 *$} \\
\hline No & 24 & 4 & 16.7 & \\
\hline Yes & 24 & 18 & 75.0 & \\
\hline
\end{tabular}

Table (3) : CEA level among cases and controls

\begin{tabular}{|c|l|l|l|l|}
\hline $\begin{array}{l}\text { CEA } \\
\begin{array}{c}\text { Median } \\
\text { Range }\end{array}\end{array}$ & $\begin{array}{l}\text { Controls } \\
(\boldsymbol{n}=\mathbf{4 8})\end{array}$ & MW & $\mathbf{P}$ \\
\hline & 5.5 & 1.25 & 25.4 & $\mathbf{0 . 0 0 1 * *}$ \\
\hline
\end{tabular}


Table 4. Relation between clinicopathological parameters and High CEA level.

\begin{tabular}{|c|c|c|c|c|}
\hline & Total & \multicolumn{2}{|l|}{$\begin{array}{c}\text { High CEA } \\
\text { No }\end{array}$} & $\mathbf{P}$ \\
\hline \multicolumn{4}{|l|}{ TNM } & \multirow{3}{*}{0.25} \\
\hline I-II & 30 & 22 & 73.3 & \\
\hline III-IV & 18 & 18 & 100.0 & \\
\hline \multicolumn{4}{|l|}{ Location } & \multirow{3}{*}{0.85} \\
\hline Colon & 28 & 22 & 78.6 & \\
\hline Rectum & 20 & 18 & 90.0 & \\
\hline \multicolumn{4}{|l|}{ PT } & \multirow{3}{*}{0.33} \\
\hline Pt 2-3 & 32 & 24 & 75.0 & \\
\hline PT4 & 16 & 16 & 100.0 & \\
\hline \multicolumn{4}{|l|}{ Histology } & \multirow{3}{*}{0.52} \\
\hline Differentiated & 36 & 30 & 83.3 & \\
\hline Undifferentiated & 12 & 10 & 83.3 & \\
\hline \multicolumn{4}{|l|}{ Size } & \multirow{3}{*}{0.71} \\
\hline$\square 5$ & 26 & 20 & 76.9 & \\
\hline$>5$ & 22 & 20 & 90.9 & \\
\hline \multicolumn{4}{|l|}{ Venous } & \multirow{3}{*}{0.65} \\
\hline No & 38 & 30 & 78.9 & \\
\hline Yes & 10 & 10 & 100.0 & \\
\hline \multicolumn{4}{|l|}{$\mathbf{L N}$} & \multirow{3}{*}{0.71} \\
\hline No & 22 & 18 & 81.8 & \\
\hline Yes & 26 & 22 & 84.6 & \\
\hline \multicolumn{4}{|l|}{ Peritoneal Mets } & \multirow{3}{*}{0.8} \\
\hline No & 40 & 34 & 85.0 & \\
\hline Yes & 8 & 6 & 75.0 & \\
\hline \multicolumn{4}{|l|}{ Liver } & \multirow{3}{*}{0.25} \\
\hline No & 30 & 22 & 73.3 & \\
\hline Yes & 18 & 18 & 100.0 & \\
\hline \multicolumn{4}{|l|}{ Chemotherapy } & \multirow{3}{*}{0.7} \\
\hline No & 22 & 18 & 81.8 & \\
\hline Yes & 26 & 22 & 84.6 & \\
\hline \multicolumn{4}{|l|}{ Recurrence } & \multirow[b]{2}{*}{0.58} \\
\hline Yes & $\begin{array}{l}24 \\
24\end{array}$ & $\begin{array}{l}18 \\
22\end{array}$ & $\begin{array}{l}75.0 \\
91.7\end{array}$ & \\
\hline
\end{tabular}




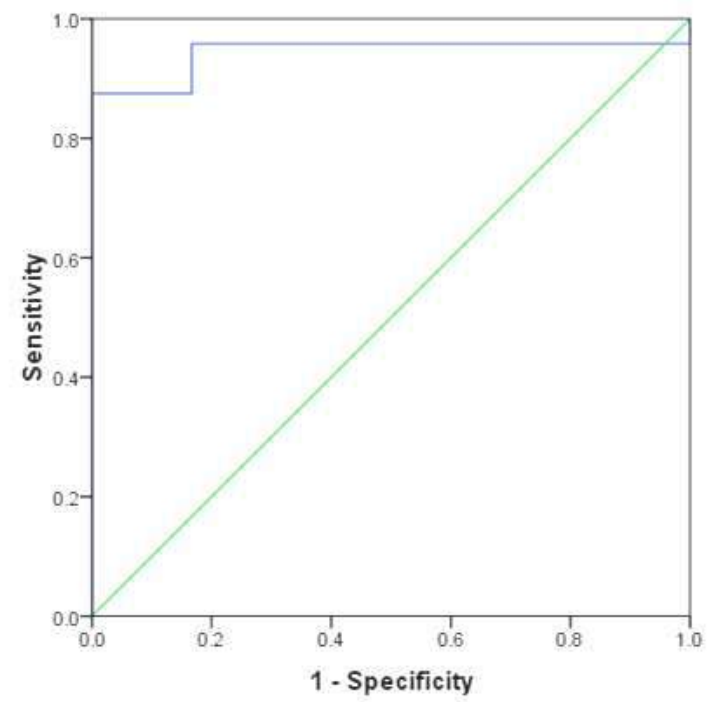

Figure 1. Receiver operating characteristic (ROC) curve analysis to evaluate serum miR-21 expression levels for the detection of CRC patients. Serum miR-21 level for the detection of CRC patients; the area under the ROC curve (AUC): 0.94, sensitivity: $95.8 \%$, and specificity: $91.7 \%$

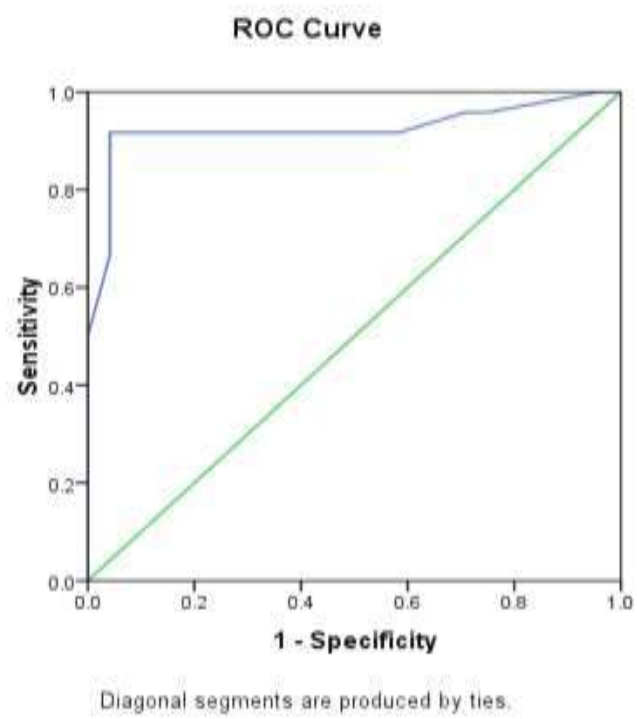

Figure 2. Receiver operating characteristic (ROC) curve analysis to evaluate serum CEA levels for the detection of CRC patients. CEA level for the detection of CRC patients; the area under the ROC curve (AUC): 0.924 , sensitivity: $83.3 \%$, and specificity: $95.8 \%$ 


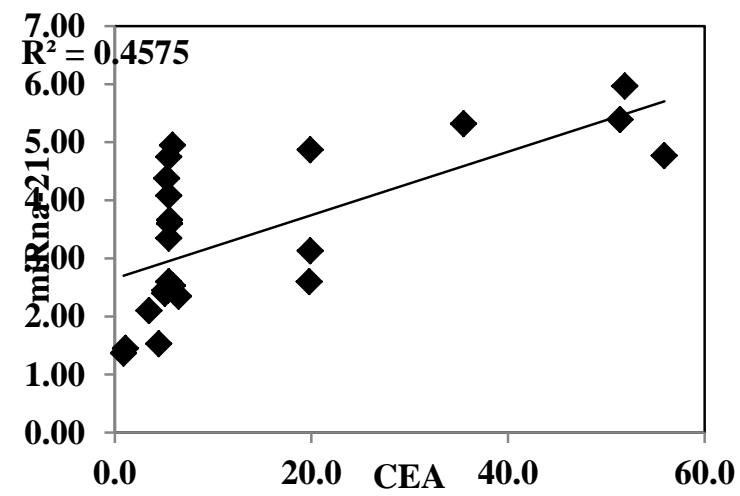

Figure 3. The figure shows highly significant correlation between CEA level and miR-21

\section{DISCUSSION}

Early CRC detection increases the overall survival rate of the patients, indicating that finding a particular, sensitive and non-invasive molecular biomarkers appropriate for early CRC diagnosis and prognosis become a must [13].

Many miRNAs have been nominated as CRC molecular biomarkers; however, a clear conclusion is hard to reach [14]. So this study aimed to clarify the predictive and prognostic value of microRNA-21 (miR-21) in patient with colorectal cancer (CRC) and correlate it with CEA as a CRC tumor marker.

No significant association was found between miR-21 expression levels and patients' clinicopathological characters, including tumor location, histological type, lymph node metastasis, peritoneal invasion and history of chemotherapy while the study revealed that the miR-21 expression level is increased in different TNM stages of CRC especially later stages.

While Bastaminejad et al. [15] study, No apparent differences were found in miR-21 levels of expression between stages III / IV, whereas there was a significant increase between stages I / II.

MiR-21 is one of the prominent miRNAs implicated in every step of cancer growth from the beginning of genesis, progression, and cancer proliferation even migration too [16].
Several articles have recently revealed the utility of serum miR-21 concentrations as a biomarker for CRC patients ' prognosis [17]. However, the clinical significance of serum miRNA as a diagnostic biomarker is still under research, and some articles have shown that serological miR-21 has no effect on CRC patients ' diagnosis $[18,19]$. One reason for this debate might be the plasma / serum miRNA are unstable and easily degraded.

Contrary to the outcomes of this research, patients with locally recurrent cancer and mortality in Menendez et al. [20] discovered reduced serum expression miR-21 and showed correlation between reduced of miR-21 expression and poor survival.

Blood-based protein biomarkers have lately been shown to be simpler methods of diagnosis of colorectal cancer, whereas their association with clinicopathological character is still under research. In this study CEA serum markers was assessed, and its connection with pathological parameters was evaluated. There were no significant association in tumor location, histological type, history of chemotherapy, TNM staging, venous invasion, liver metastasis, LN and peritoneal metastasis and recurrence.

Previous investigators have reported that CEA promotes cancer cell metastases and invasion by targeting the adherence junction complexes between cells and enhancing the aggregation of cells [21, 22]. 
However, no significant difference was found in the tumor number according to CEA level in our study. CEA has also been demonstrated to be involved in suppressing the immunity by inducing the release of suppressor factor from normal lymphocytes [23, 24]. These underlying biological mechanisms may explain why patients had a high CEA levels.

Meanwhile Menendez et al., (20) recognized age $(\mathrm{p}=0.028)$, tumor phase $(\mathrm{p}=0.003)$, CEA level $(\mathrm{p}=0.001)$ and miR-21 level of speech $(\mathrm{p}=0.004)$, as autonomous predictor of CRC excellent prognosis

A highly significant correlation between CEA level and miR-21 has been proved in our study Although our results are promising, there are still several constraints to our research. First, this study included only serum samples. Further studies using the serum miR-21 in comparison with the expression of tissue would obviously strengthen our results. Second, the small sample size in this work highlights the need of further reports including big cohorts are needed for more clear validation of the miR-21 assay. Finally, the cost of this technique should be considered in future similar studies.

\section{CONCLUSION}

The findings indicate that the circulating serum concentration miR-21 may be a hopeful tumor marker used in prediction of cancer outcome and its determination may be able to pick candidate patients for more aggressive treatment or use novel therapeutic alternatives to correct abnormal miRNAs, also strong correlation were found between miRNA-21 and CEA as a prognostic marker.

\section{RECOMMENDATIONS}

We therefore add miR-21 as a serum miRNAs that are associated with poorer prognoses in CRC patients. More research is needed to understand the precise role of circulating miR21 in oncology whether oncogenes or antioncogene, depending on its target, so additional studies on miR-21 become mandatory. Large-scale multicentre prospective studies with increasing the sample size are warranted to verify the results.

\section{Declaration of interest}

The authors report no conflicts of interest. The authors alone are responsible for the content and writing of the paper.

\section{Funding information}

None declared

\section{REFERENCES}

1. Jemal A, Siegel R, Xu J, Thun MJ.: Cancer statistics, 2010. CA Cancer J Clin 2010; 60: 277-300

2. Chang KH, Miller N, Kheirelseid EA, Lemetre C, Ball GR, Smith MJ. MicroRNA signature analysis in colorectal cancer: Identification of expression profiles in stage II tumors associated with aggressive disease. Int $\mathbf{J}$ Colorectal Dis 2011; 26: 1415-22.

3. Malafosse R, Penna C, Sa Cunha A, Nordlinger B. Surgical management of hepatic metastases from colorectal malignancies. Ann Oncol 2001; 12: 887-894

4. Fan Y, Zhu X, Lan Q, LouF, Zheng Y, Lou H, et al. Thermal radiofrequency ablation as an adjuvant therapy for patients with colorectal liver metastasis. Oncol Res 2016; 23: 219-28.

5. Aslam MI, Taylor K, Pringle JH, Jameson JS. MicroRNAs are novel biomarkers of colorectal cancer. Br J Surg 2009; 96: 702-710.

6. Lujambio A, Calin GA, Villanueva A, Ropero S, Sánchez- Céspedes $\mathrm{M}$, Blanco $\mathrm{D}$, et al. A microRNA DNA methylation signature for human cancer metastasis. Proc Natl Acad Sci USA 2008; 105: 13556-13561

7. Peacock O, Lee AC, Larvin M, Tufarelli C, Lund JN. MicroRNAs: relevant tools for a colorectal surgeon? World J Surg 2012; 36: 1881-1892

8. Okayama H, Schetter AJ, Harris CC. MicroRNAs and inflammation in the pathogenesis and progression of colon cancer. Dig Dis 2012; 30 (Suppl 2): 9-15.

9. Tang JT, Fang JY. MicroRNA regulatory network in human colorectal cancer. Mini Rev Med Chem 2009; 9: 921-926.

10. Montano M. MicroRNAs: miRRORS of health and disease. Translat res 2011; 157(4): 157-162.

11. Mazeh H, Mizrahi I, Ilyayev N, Halle D, Brücher BL, Bilchik A, et al. The diagnostic and prognostic role of microRNA in colorectal cancer-a comprehensive review. J Cancer 2013; 4(3): $281-295$. 
12.Livak KJ, Schmittgen TD. Analysis of relative gene expression data using real-time quantitative PCR and the 2 (-Delta Delta C(T)) Method. Methods 2001; 25 (4): 402-408.

13. Bresalier RS, Kopetz S, Brenner DE. Bloodbased tests for colorectal cancer screening: do they threaten the survival of the FIT test? Dig dis Sci 2015; 60 (3): 664-671.

14.Ma Y, Zhang P, Yang J, Liu Z, Yang Z, Qin H. Candidate microRNA biomarkers in human colorectal cancer: systematic review profiling studies and experimental validation. Internat $\mathbf{J}$ Cancer 2012; 130 (9): 2077-2087.

15.Bastaminejad S, Taherikalani M, Ghanbari R, Akbari A, Shabab N, Saidijam M. Investigation of microRNA-21 expression levels in serum and stool as a potential non-invasive biomarker for diagnosis of colorectal cancer. Iran Biomed J 2016; 21: 106-13.

16. Nedaeinia R, Sharifi M, Avan A, Kazemi M, Rafiee L, Ghayour-Mobarhan M, et al. Locked nucleic acid anti-miR-21 inhibits cell growth and invasive behaviors of a colorectal adenocarcinoma cell line: LNA-anti-miR as a novel approach. Cancer Gene Ther 2016; 23: 246-253.

17. Kanaan Z, Rai SN, Eichenberger MR, Roberts H, Keskey B, Pan J, et al. Plasma miR-21: a potential diagnostic marker of colorectal cancer. Ann Surg 2012; 256: 544-551

18. Almeida AL, Bernardes MV, Feitosa MR, Peria FM, Tirapelli DP, Rocha JJ, et al. Serological under expression of microRNA-21, microRNA- 34a and microRNA-126 in colorectal cancer. Acta Cir Bras 2016; 31 (Suppl 1): 13-18.

19.Montagnana M, Benati M, Danese E, Minicozzi AM, Paviati E, Gusella $M$, et al. Plasma expression levels of circulating miR-21 are not useful for diagnosing and monitoring colorectal cancer. Clin Lab 2016; 62: 967-970.

20. Menendez P, Padilla D, Villarejo P, Palomino T, Nieto P, Menendez JM, et al. Prognostic implications of serum microRNA-21 in colorectal cancer. J Surg Oncol 2013; 108: 369373.

21.Pignatelli M, Durbin $\mathrm{H}$, Bodmer WF. Carcinoembryonic antigen functions as an accessory adhesion molecule mediating colon epithelial cell-collagen interactions. Proc Natl Acad Sci USA 1990; 87: 1541-5.

22.Bajenova O, Chaika N, Tolkunova E, DavydovSinitsyn A, Gapon S, Thomas P. Carcinoembryonic antigen promotes colorectal cancer progression by targeting adherens junction complexes. Exp Cell Res 2014; 324: 115-23.

23. Hakim AA. Carcinoembryonic antigen, a tumorassociated glycoprotein induces defective lymphocyte function. Neoplasma 1984; 31: 385-97.

24.Medoff JR, Jegasothy BV, Roche JK. Carcinoembryonic antigen-induced release of a suppressor factor from normal human lymphocytes in vitro. Cancer Res 1984; 44: 5822-7.

To Cite This Article: Gharib AF, Mohamed RH, Abdel-Fatah AR, Saadawy SF. Association between Serum MicroRNA-21 Gene Expression, Carcinoemberyonic Antigen and Clinicopathological Character for Colorectal Cancer. ZUMJ 2019; 25 (5): 673-681. Doi 10.21608/zumj.2019.14149.12920. 